\title{
Conservação ambiental, turismo e população local
}

\author{
Helena Catão Henriques Ferreira* \\ Maria José Carneiro**
}

\section{Resumo}

A criação de Unidades de Conservação da Natureza, tem desencadeado processos de mudanças nas localidades. Devido as regulações impostas pela legislação as populações moradoras são impelidas a modificar suas formas de apropriação dos recursos naturais, A conservação destas unidades vem ao encontro de uma demanda das populações urbanas por um contato maior com os ambientes tidos como "naturais"estimulando um fluxo crescente de turistas em direção a elas. Os habitantes, cerceados em suas atividades e práticas costumeiras e também impelidos pela pressão econômica do turismo voltam-se para a prestação de serviços a estes visitantes. 0 espaço rural passa então a ser apreendido como espaço ambiental e visto como "paraíso", dando origem a novos territórios sociais. No caso da Vila do Aventureiro, na Ilha Grande, estes processos ocorrem em razão do estabelecimento de duas unidades de conservação: a Reserva Biológica da Praia do Sul e o Parque Estadual Marinho do Aventureiro. A proposta deste trabalho é refletir sobre o contraste entre a perspectiva preservacionista instalada na localidade e as transformações sociais que este processo desencadeia.

Palavras-chave: CADMA, Conservação Ambiental, Turismo , População Local

\section{Abstract}

The creation of Environment Conservation Units has unleashed processes of change in the localities. Due to the regulations imposed by the legislation the populations are impelled to modify their ways of appropriation of natural resources. The conservation of these areas matches an urban population demand for a greater contact with places considered as 'natural', which encourages a flux of tourists towards them. The inhabitants, restricted to their usual practices and activities and also impelled by the economic pressure of tourism, turn to the rendering of services to these visitors. Thus, the rural area begins to be apprehended as environmental space and seen as 'paradise', originating new social territories. In the case of Vila do Aventureiro, in Ilha Grande, these processes occur due to the establishment of two conservation units: the Reserva Biológica da Praia do Sul and the Parque Estadual Marinho do Aventureiro. The proposition of this work is to reflect on the contrast between the preserving perspective installed in this area and the social transformations that this process unleashes.

Key words: CADMA, Environment Conservation, Tourism, Local Populations

\section{Introdução}

Este artigo é uma reflexão sobre as implicações da implantação de unidades de conservação da natureza na vida dos moradores dessas áreas. A reserva de áreas consideradas ambientalmente relevantes - uma das principais estratégias do movimento ambientalista no Brasil e no mundo - desencadeia um novo arranjo nas relações sociais locais. Nesse processo, ocorre uma "requalificação do território", uma "requalificação do local" como lugar de gestão do meio ambiente (MORMONT,1996). O território, visto como a apreensão do espaço por um determinado grupo social (RAFFESTIN,1986), multiplica-se em novos territórios sociais que se conformam à medida que novos grupos entram em cena, com novas regras e novas historicidades, disputando entre si a hegemonia na apreensão desse espaço, o direito de usá-lo e legitimá-lo conforme suas próprias demandas.

\footnotetext{
* Companhia de Turismo do Estado do Rio de Janeiro- Turisrio. Mestre pelo curso de Pós-Graduação em Desenvolvimento, Agricultura e Sociedade (CPDA) da Universidade Federal Rural do Rio de Janeiro (UFRuralR). E-mail: lelecatao@superig.com.br. Endereço: Rua da Ajuda 05 - $6^{\circ}$ andar - CEP: 20 040-000. Rio de Janeiro $-\mathbf{R J}$.

* Professora do curso de Pós-Graduação em Desenvolvimento, Agricultura e Sociedade (CPDA) da Universidade Federal Rural do Rio de Janeiro (UFRuralRJ). Doutora em Antropologia Social. E-mail: mjcarneiro@terra.com.br. Endereço: CPDA/UFRR. Av. Presidente Vargs, 417, 9. andar. CEP 20071-003 - Rio de Janeiro, RJ. 
Instala-se, assim, um enfrentamento entre diferentes formas de uso do espaço, determinadas pela cultura da população nativa e pelos interesses externos e globalizados.

A concepção de unidades de conservação da natureza traz em si a idéia de separação dessas unidades do ambiente em geral, tidas como um sistema fechado, distintas do contexto mais amplo no qual estão inseridas. Na prática, contudo, tem sido difícil sustentar esse modelo devido às pressões econômicas, sociais e ambientais. Comumente, essas dificuldades são atribuídas à falta de recursos e de vontade política dos governos para a implantação dessas unidades de conservação, sem que se cogite sobre a responsabilidade do próprio modelo em que são concebidas. Uma das questões mais complexas no momento de se instituir uma unidade de conservação diz respeito à população local. Nessas áreas são impostos diversos tipos de regulações, acarretando mudanças nas formas de apropriação e atuação desses moradores em relação aos recursos naturais, o que comumente gera conflitos com os gestores das unidades. Os moradores tendem a resistir às modificações em seus costumes, levando-se em conta que está em jogo não apenas sua reprodução cultural mas também sua sobrevivência (DIEGUES, 1996).

Para discutir essa questão, foi considerado o caso da Vila do Aventureiro, na Ilha Grande, no estado do Rio de Janeiro. Lá foram criadas duas unidades de conservação da natureza pertencentes à categoria de proteção integral: a Reserva Biológica Estadual da Praia do Sul, em 1981, e o Parque Estadual Marinho do Aventureiro, em 1990. A Vila do Aventureiro, fica no sudoeste da Ilha Grande e há cerca de 150 anos é habitada por agricultores/pescadores chamados de "caiçaras". Durante longo tempo, essa população viveu exclusivamente da agricultura de subsistência e da pesca artesanal, e partir da década de 1990 presenciou a expansão da atividade turística.

A criação das unidades de conservação e, posteriormente, o crescimento do turismo têm desencadeado mudanças no modo de vida dessa população, gerando tensões sociais que serão aqui abordadas.

Esse estudo é baseado em pesquisa de campo feita na Vila do Aventureiro, entre novembro de 2003 e janeiro de 2004, para uma dissertação de mestrado. Nessa pesquisa optou-se por uma abordagem qualitativa, apoiada em técnicas de construção de histórias de vida e na observação direta. A Vila do Aventureiro foi escolhida como objeto de pesquisa por apresentar importantes elementos desse debate. A unidade de conservação em questão é uma reserva biológica - portanto, o tipo mais restritivo dessa forma legal -, onde não é permitida a presença de moradores, nem de turistas. A comunidade local não está no entorno da unidade, mas dentro da reserva, e é considerada pelos ambientalistas a mais tradicional população caiçara do estado do Rio de Janeiro. Quanto à biodiversidade, a região é uma das mais ricas do estado, pela grande variedade de ecossistemas existentes. Apesar disso, hoje, a localidade tem no grande fluxo turístico, sua principal fonte de sustento. Daí surgem conflitos, contradições e transformações, que são aspectos particularmente ricos para se discutir as questões propostas.

\section{A Ilha Grande e suas unidades de conservação}

Localizada na região sul do estado do Rio de Janeiro, na baía do mesmo nome, a Ilha Grande pertence ao município de Angra dos Reis e é a maior ilha do estado, com uma área de $193 \mathrm{~km}^{2}$. Seu relevo é bastante acidentado, tem 106 praias e diversos cabos e enseadas. Os numerosos cursos d'água que descem das montanhas formam o sistema hidrográfica da ilha e abastecem a população local.

Área de domínio da Mata Atlântica e de ecossistemas marinhos associados, originalmente a ilha deve ter sido coberta por densa floresta. No entanto, esse quadro se alterou devido aos ciclos econômicos como o do extrativismo de madeira, o do açúcar, do café, e até da criação de gado, além de atividades mais recentes como o turismo. O lado da ilha voltado para o continente é o que sofreu maior impacto do ponto de vista antrópico, pois foi o primeiro a ser ocupado, uma vez que suas águas são abrigadas, facilitando o acesso. É justamente pela maior dificuldade de acesso, que a parte oceânica e os lugares mais altos têm a cobertura vegetal mais conservada. É nessa parte, voltada para o mar aberto, que fica a Vila do Aventureiro. 
Com o propósito de conservar suas florestas e proteger seus ecossistemas, a ilha tem sido alvo de decretos e leis ambientais desde a década de 1970. Desde então, foram estabelecidas diversas unidades de conservação, algumas inclusive se sobrepondo. São elas o Parque Estadual da Ilha Grande, de 1971, administrado pelo Instituto Estadual de Florestas (IEF), a Reserva Biológica Estadual da Praia do Sul, a Área de Proteção Ambiental dos Tamoios e o Parque Estadual Marinho do Aventureiro, - administrados pela Fundação Estadual de Engenharia do Meio Ambiente (Feema) - e a Reserva Biológica da Ilha Grande, criada em 1987, abrangendo toda a ilha. Esta não é considerada pelos órgãos ambientais, pois além da sobreposição às outras unidades de conservação, sua instalação criou uma situação inteiramente contraditória, uma vez que, segundo seu decreto de criação, não poderia haver em toda a Ilha Grande nenhum tipo de ocupação humana.

\section{A Reserva Biológica Estadual da Praia do Sul}

Criada pelo Decreto estadual no 4.972 de 2-12-1981, a reserva engloba terras à sudoeste da Ilha Grande, voltadas para o Oceano Atlântico. A reserva biológica é um dos mais antigos e restritivos tipos de unidade de conservação existentes no Brasil, conforme a lei do Sistema Nacional de Unidades de Conservação (SNUC), sancionada em 2000 pelo então presidente da República, Fernando Henrique Cardoso, e regulamentada em 2002:

Reserva Biológica tem como objetivo a preservação integral da biota e demais atributos naturais existentes em seus limites, sem interferência humana direta, ou modificações ambientais, excetuandose as medidas de recuperação de seus ecossistemas alterados e as ações de manejo necessárias para recuperar e preservar o equilibrio natural, a diversidade biológica e os processos ecológicos naturais (BRASIL, 2000, art.10, p.10).

A criação da Reserva Biológica Estadual da Praia do Sul foi justificada pela equipe da Feema, que coordenou o processo, por tratar-se do último conjunto de ecossistemas do litoral do estado do Rio de Janeiro a reunir restinga, manguezal, litoral rochoso e mata de encosta, com vegetação ainda em bom estado de preservação (MACIEL, ARAÚJO e MAGNANINI, 1980). Durante os trabalhos de campo da pesquisa que precedeu a criação da unidade, foram encontradas também três jazidas pré-históricas para polimento de armas e ferramentas de pedra. A acelerada expansão do turismo na região sul fluminense, principalmente após a abertura da rodovia BR-101, contribuiu para apressar a proteção legal da área.

Em 1979, a Empresa Brasileira de Turismo (Embratur) aprovou um projeto de ocupação turística e de loteamento de parte da Praia do Sul. O assunto foi estudado pela Feema, levado à Comissão Estadual de Controle Ambiental (Ceca), foi feita uma pesquisa detalhada sobre os ecossistemas da área e, então, criada a reserva.

Para os técnicos que atuaram em todo esse processo, o local era desabitado, com exceção de uma pequena faixa de areia, a praia do Aventureiro, onde moravam cerca de 30 famílias não muito numerosas. Depois de criada a reserva, a Feema decidiu transferir essas famílias para Angra dos Reis, considerando que não é permitido morar numa reserva biológica. Contudo, quando era feita a transferência, houve uma mudança política no órgão e a nova equipe, que tinha outra visão do problema, defendia a permanência dos moradores no Aventureiro. Foi então elaborado um plano diretor para a reserva. Esse plano, aprovado pelo Conselho Superior da Feema, definiu outra área para a unidade de conservação, deixando a praia do Aventureiro de fora. Até hoje, entretanto, esse plano não foi implantado, e os limites da reserva são os mesmos da época de sua criação, incluindo, portanto, a praia do Aventureiro e os morros circundantes onde, atualmente, vivem cerca de 103 pessoas.

É curioso observar que mesmo proibido qualquer tipo de ocupação humana numa reserva biológica, os mentores da Reserva Biológica da Praia do Sul incluíram a Vila do Aventureiro em sua área. No estudo da Feema de 1980, foram descritos os principais núcleos pesqueiros da ilha, e entre eles, a vila. Em outra pesquisa (FEEMA,1982), um levantamento sobre a hidrografia, o relevo e as trilhas da reserva, com base na tradição oral do local, revelou que os nomes dos rios e morros eram associados aos nomes das pessoas, das famílias e também das roças espalhadas pela região, demonstrando o estreito vínculo entre a população e o meio 
ambiente. Mesmo assim, a concepção de natureza e de conservação que levou à criação da reserva ignorava a população em seu projeto.

\section{Parque Estadual Marinho do Aventureiro}

O parque foi criado pelo Decreto estadual no 15.983 de 27-11-1990 que proibiu a exploração dos recursos naturais, especialmente a pesca, e qualquer "atividade potencialmente poluidora". Sob o controle da Feema, é permitido a pesca artesanal, as atividades de pesquisa científica, o turismo ecológico e a educação ambiental. A área do parque cobre a parte marítima de 5 milhas náuticas que margeia a Reserva Biológica Estadual da Praia do Sul. Seu nome se refere ao núcleo populacional de pescadores lá existente, e nele estão incluídas a zona de marés e a desembocadura dos rios. O parque engloba ainda todo o volume de mar do espelho d'água daquela reentrância natural da ilha, bem como os meios físicos e bióticos existentes da superfície até o fundo do mar, segundo o Atlas das Unidades de Conservação da Natureza do Estado do Rio de Janeiro (SEMADS-RJ, 2001). Ainda segundo o atlas, o parque foi criado para preservar atributos excepcionais da natureza, compatibilizandoos com usos voltados para a educação ambiental, a recreação, o turismo ecológico e a pesquisa científica.

Uma das finalidades da criação do parque parece ser a de complementar a proteção à reserva, regulando as demais atividades marítimas. Todavia, cabe observar que a legislação do parque, na medida em que admite a pesca artesanal e o turismo ecológico, entra em conflito com a legislação da reserva. A pesca artesanal, permitida pelo decreto de criação do parque, sugere que na região há uma população que tem esse elemento na sua cultura, o que não é permitido pela reserva. Além disso, o turismo ecológico - atividade com foco nos recursos naturais preservados -, que prevê o planejamento visando à conservação desses recursos, certamente, não se sustentaria somente em área marinha. Seria necessário que fossem estabelecidas infra-estrutura e atividades também em terra. Portanto, a delimitação de fronteiras do parque entra em choque com a imposta pela reserva, já que necessariamente o que ocorre no mar tem continuidade no que acontece em terra. Assim, a criação dessas duas unidades de conservação foi calcada em conceitos ambientalistas biocêntricos, considerando as áreas de proteção integral como as mais importantes para a conservação e excluindo a presença de moradores.

\section{Unidades de conservação e populações humanas}

A relação entre a administração de unidades de conservação e as populações que vivem no entorno ou dentro dessas áreas tem sido um dos maiores desafios para o conservacionismo. O termo "áreas protegidas", usado mundialmente, revela a concepção de conservação ambiental desse modelo. Supõe que a ação da sociedade sobre a natureza fisica e biológica é necessariamente destrutiva. Sugere também que é através da reserva e da proteção de "pedaços" dessa natureza que se poderá conservar o aspecto original de parte do planeta, visando à elaboração de pesquisas, de bancos genéticos, à proteção dos recursos hídricos ou ao desfrute das populações urbanas. Portanto, o papel dos órgãos ambientais responsáveis pelas unidades de conservação tem sido o de controlar e, em alguns casos, tentar impedir os usos sociais demandados pelos moradores dessas áreas ou das cercanias. Daí surgem conflitos, a medida em que essas pessoas tendem a resistir às modificações em seus costumes, pois o que está em jogo é a sua reprodução sociocultural.

No âmbito internacional, as organizações ambientalistas têm discutido a presença humana nas áreas protegidas, desde as décadas de 1960 e 1970. Na anos 1980, o debate sobre populações e conservação ambiental já avançara bastante, tornando-se um tema recorrente nos congressos mundiais de parques nacionais. Esse discussão se concentrava na crítica à expulsão das chamadas "populações tradicionais" das unidades de conservação, no reconhecimento da estreita relação dessas populações com seus ecossistemas (diferenciando-se das populações urbano-industriais) e na necessidade de sua participação no controle e no uso dos recursos naturais. Em 1992, no IV Congresso Mundial de Parques, em Caracas, intitulado "Povos e Parques", ficou patente a preocupação com essas populações, vistas como grandes conhecedoras de seus ecossistemas e participantes de sua conservação (DIEGUES, 1996). 
No Brasil, no entanto, essas idéias chegaram com um certo atraso e dificuldade. A implantação do modelo econômico conhecido como Milagre Brasileiro, nos anos 1970, desencadeou um crescimento rápido da economia, com o incentivo à industrialização a qualquer preço e à criação de projetos gigantescos, como os dos centros petroquímicos. Por sua vez, a Revolução Verde, em curso desde a década anterior, modernizou a agricultura e incentivou a produção em larga escala de maquinário e insumos químicos agrícolas, ainda que em contrapartida tenha propiciado a concentração de terra e de renda. Esses fatores causaram forte impacto ambiental e social no Brasil. Como uma espécie de contrapartida, entre 1970 e 1986 - boa parte desse período ainda sob o regime militar encerrado em 1985 - foi criada a maioria das unidades de conservação hoje existentes no país (DIEGUES,1996). Era familiar aos militares, a lógica do modelo de unidades de conservação de proteção integral, pela qual uma área é cercada para ser protegida contra os inimigos (URBAN, 1998). Provavelmente isso influenciou a forma autoritária como essas unidades foram criadas, sem a participação das populações envolvidas e nem da sociedade em geral.

A redemocratização do país e a entrada em cena dos movimentos sociais contribuíram para o questionamento desse modelo e para a compreensão, por diversos setores da sociedade, da existência de diferentes formas de organização social e territorial. Contudo, até hoje, predomina o modelo de unidades de conservação que não admite a presença de habitantes; tanto é assim que o Sistema Nacional de Unidades de Conservação (SNUC) proíbe claramente a moradia nas unidades do tipo "proteção integral".

Nesse contexto, as chamadas "populações tradicionais" se tornam importantes, pois são consideradas as principais personagens nessas disputas e as únicas em relação as quais se reconhece algum direito sobre essas áreas. Entretanto, a noção de "populações tradicionais" suscita muita polêmica, e foi um dos principais pontos de discórdia durante a longa tramitação da lei do SNUC. O motivo dessa polêmica foi a dificuldade de se saber até que ponto um grupo tem ou não as características que o definiriam como "tradicional"? De se definir quantas e quais dessas características levam um grupo a receber tal classificação? Além do mais, o termo pressupõe a idéia de uma sociedade estática, congelada em determinados padrões, ignorando-se a dinâmica da reprodução sociocultural.

\section{Os habitantes do Aventureiro e as unidades de conservação}

A comunidade do Aventureiro vê de modo muito diferente cada uma das duas unidades de conservação locais. Para eles, a reserva biológica é algo mais concreto do que o parque estadual marinho. As regulações legais da reserva interferem diretamente na posse da terra e na possibilidade ou impossibilidade de suas práticas culturais. O parque, entretanto, é desconhecido pela maioria das pessoas. Sua existência parece ser apenas formal. Suas normas em relação à pesca e também as proibições em relação às práticas consideradas predatórias - como, por exemplo, o arrasto - são identificadas pelos pescadores como comuns à todas as localidades da Ilha Grande e não especiais de um parque marinho. As duas unidades de conservação têm afetado a vida da população do Aventureiro e provocado, por diversos fatores, sentimentos ambíguos. Se por um lado admitem que, de certa forma, têm conseguido se livrar da especulação imobiliária que assola o restante da ilha, por outro, sentem que a Feema exerce um controle sobre seu estilo de vida.

A mata, que hoje cresce por toda parte, encobre roças que um dia ali existiram, encobre uma história vivida, um trabalho "impresso" nas terras. Apaga, portanto, parte de uma rede de relações que existiu entre os agricultores com sua sociabilidade ligada aos mutirões. $\mathrm{O}$ decreto da unidade de conservação prevê a preservação dos ecossistemas e dos restos arqueológicos de populações extintas há longa data. Mas, ao mesmo tempo, apaga uma história ainda presente. Ao perder o direito às roças, a comunidade também perde parte dos laços afetivos e de sua memória.

$\mathrm{Na}$ prática, essa população vive as conseqüências do embate teórico entre questões que mobilizam historicamente o ambientalismo. A visão biocêntrica e a que respeita a permanência da população local; pontos de vista que, entretanto, têm se atualizado. Mesmo assim, a comunidade ainda corre o risco de ser expulsa. Nela, as opiniões estão divididas sobre quase todos os aspectos que envolvem seu cotidiano, como se o simples fato de existirem em seu ambiente, herdado dos antepassados, fosse motivo de polêmica. 
Vivendo numa das praias de mais difícil acesso da Ilha Grande, devido às condições do mar aberto a que está exposta e à declividade acentuada dos morros circundantes, essa população viveu um relativo isolamento até a década de 1990. Para algumas correntes ambientalistas, a lavoura e a pesca artesanal comprovam as "raízes caiçaras", consideradas sob ameaça de extinção pelo turismo em expansão. Para outras correntes, no entanto, essas "raízes" já estariam praticamente extintas e descaracterizadas.

\section{Turismo, transformação e "ressignificação" do lugar}

Em 1994, o governo estadual resolveu desativar o Instituto Penal Cândido Mendes, conhecido genericamente como "o presídio". Embora Wunder (2000) questione essa idéia, a existência do presídio na ilha parece ter sido determinante para frear o desenvolvimento do turismo no local. A partir do momento em que o governo implodiu a maior parte de suas instalações e transferiu os detentos para presídios recém-construídos em Bangu (na Zona Oeste do Rio), a atividade turística cresceu de forma intensa e abrupta em toda a Ilha Grande, com reflexos no até então incipiente movimento turístico no Aventureiro.

Ao contrário da década anterior, quando o meio rural tinha uma imagem negativa e associada ao atraso, no final da década de 1960, o mundo ocidental começou a ser varrido por uma onda de valores críticos ao estilo de vida urbano-industrial, com uma visão positiva do ambiente não-urbano, da vida em espaços rurais. Intensificou-se, então, a procura por lazer e até mesmo por moradia no campo por parte dos que viviam nas cidades, num "renascimento rural" (KAYSER, 1990). O apelo ao reencontro com a natureza e o respeito ao meio ambiente associa-se a um movimento de crítica à idéia de progresso contínuo que, desde os primórdios da industrialização no mundo, permeou o pensamento hegemônico. Essa crítica é contemporânea à intensificação do processo de globalização que projetou a noção de uma sociedade planetária e acelerou a circulação das idéias, instalando um sentimento de relatividade e incerteza. Tomou forma, então, uma "ressignificação" da idéia de ruralidade, surgindo novas imagens a respeito do rural, estimuladas por sentimentos de nostalgia nas cidades em relação a um "mundo tradicional agrário perdido" (DURÁN, 1998). Refletindo sobre a contemporaneidade, Moreira (2002, p.1) registra o aparecimento de rurais "sem território e sem natureza", ou rurais tradicionais vivenciados nas cidades e no presente, concebidos como simulacros, representações e virtualidades. $\mathrm{O}$ contato com a natureza foi realçado por valores alternativos, neo-ruralistas e antidesenvolvimentistas. $\mathrm{O}$ ar puro, a simplicidade da vida e a natureza são vistos como elementos purificadores do corpo e do espírito poluídos pela sociedade industrial (CARNEIRO, 1998, p.57). Esse movimento deu origem a um tipo de turismo que transforma a natureza em mais um bem de consumo. Dessa forma, as áreas naturais, sobretudo as protegidas, transformam-se em grande atração, tanto para quem vive nos países onde elas se situam quanto para turistas estrangeiros (CEBALLOS-LASCURÁIN, 1995).

A demanda das populações urbanas por áreas naturais é atribuída, por um lado, à vida conturbada e estressante das grandes cidades e, por outro, à propagação de conceitos e visões sobre a natureza, principalmente o apreço pelo mundo selvagem trazidos pelo ambientalismo, que estimulou a produção de uma grande quantidade de documentários e programas de televisão sobre ecologia, vida animal, locais distantes e desertos, florestas, parques nacionais e, mais recentemente, culturas exóticas. A difusão dessas imagens impulsionou de tal forma essa demanda que, hoje, um dos principais problemas das áreas protegidas é lidar com o enorme contingente de turistas.

No Aventureiro, a paisagem que esse tipo de turista valoriza foi favorecida pelo processo de regeneração da floresta em meio às roças restantes, e pela proximidade de áreas montanhosas em relação ao mar. Com as roças reduzidas, as que sobraram se misturam à mata em regeneração e às capoeiras do pousio. Esse mosaico de vegetação - de onde sobressaem coqueiros em profusão, bananeiras, amendoeiras e jaqueiras, contando a história da população local e de seus antepassados - dá um aspecto exótico à paisagem, chamada de "paraíso" pelos turistas.

As unidades de conservação são freqüentemente associadas à noção de "ilhas de conservação", em meio à natureza totalmente transformada pela sociedade. Assim, o Aventureiro pode ser visto como uma ilha dentro da ilha, transmitindo uma sensação de isolamento que é reforçada pelas dificuldades de acesso. 
A imagem paradisíaca tem sido apropriada constantemente pelo turismo. É associada a sentimentos de liberdade, de permissividade e de aventura, de contato com um mundo supostamente selvagem e "autêntico". Ao mesmo tempo em que há o desejo de se correr riscos, há a necessidade de que esses riscos sejam de alguma forma controlados, de que estejam disponíveis meios de transporte com alguma segurança, de que sejam disponibilizadas informações que possibilitem ao visitante se orientar no ambiente inóspito.

O turismo desenvolvido no Aventureiro tem sido visto, principalmente, pelo órgão ambiental responsável pela área e por ambientalistas, como motivo de preocupação. O debate em torno dele está polarizado entre posições mais radicais, segundo as quais qualquer forma de turismo deve ser combatida por ser ilegal numa reserva biológica, e outras mais condescendentes com a forma particular de turismo, conhecida como ecoturismo. A primeira alternativa é difícil de ser implementada. Apesar dos moradores terem uma opinião ambígua em relação ao turismo - pois o vêem como uma atividade que tanto traz problemas quanto benefícios reconhecem que é uma alternativa econômica importante, da qual não pretendem abrir mão. Além disso, o interesse pela região é crescente, tornando extremamente difícil impedir o acesso de turistas ao local, dado o interesse da população em facilitar esse acesso.

Em resposta à demanda das populações urbanas por áreas naturais e também como uma crítica ao turismo de massa, surge, nas duas últimas décadas do século XX, o chamado turismo ecológico, mais tarde, conhecido como ecoturismo. O turismo de massa surgiu após a II Guerra Mundial e se caracteriza pelo grande número de pessoas viajando, por ser um importante gerador de empregos e pelas altas cifras que movimenta (GEIGER, 1996). Como ressalta Krippendorf (1989), desde então uma "mobilidade frenética" tomou conta das populações dos países industrializados. Acreditando agir por livre determinação, e ao mesmo tempo aparentando cumprir uma obrigação, muita gente se desloca a cada fim de semana, nos feriados ou em períodos de férias para locais lotados, onde enfrentam filas nos pontos turísticos. Conquistas sociais como férias remuneradas e o desenvolvimento dos meios de transporte e de comunicação foram fundamentais para que o fenômeno ocorresse.

Durante muito tempo, o crescimento incessante, em nível mundial, do turismo e sua organização - comparada à indústria do período fordista - criaram produtos turísticos padronizados, conquistando mercados e estimulando nas pessoas a necessidade de viajar. As localidades nas quais o turismo se instalava comemoravam o crescimento da oferta de emprego e a dinamização da economia. A modernização, por conta da necessidade dos turistas de encontrar conforto urbano em qualquer lugar, era bem-vinda por ser entendida como progresso.

Contudo, nas últimas décadas do século XX, esse modelo de desenvolvimento turístico começou a dar sinais de esgotamento. A "indústria sem chaminés" mostrou que poderia ser tão poluente ou destruidora quanto qualquer fábrica. O estímulo à especulação imobiliária, o aumento do custo de vida, a destruição de ecossistemas para a construção de grandes empreendimentos hoteleiros, o estímulo às migrações e a superpopulação foram apenas alguns dos inúmeros fatores que transformaram a vida de pequenos lugarejos.

Foi como crítica a esse modelo, mas também em sintonia com as novas tendências do capitalismo, que surgiram propostas de um turismo alternativo e sustentável. Um turismo que respeitasse a capacidade de carga dos meios de acolhimento - em termos naturais, culturais e sociais -, preservando os recursos locais, físicos e humanos, inclusive os de interesse turístico; e que reduzisse custos, proporcionando mais benefícios (CAVACO, 1996, p.105). Um turismo que tem no ecoturismo seu mais antigo representante.

\section{Turismo e população local}

O turismo é visto pelas populações que o consomem como uma forma de ocupação de seu "tempo livre", o tempo do "não-trabalho". Para as comunidades receptoras significa oportunidade de trabalho e fator de transformação em suas vidas; um fenômeno multifacetado que contribui decisivamente para redefinir a fisionomia espacial e as relações econômicas e sociais locais.

Inúmeras transformações ocorrem nas localidades que passam a ser consideradas territórios turísticos. Como lembra Nicolas (1996), mais do que uma atividade econômica, o turismo é uma prática geradora de atividade 
econômica. A demanda criada pelo turista em relação a transporte, alojamento, alimentação ou recreação acaba desenvolvendo uma vasta gama de negócios e criando empregos. Mesmo assim, apesar da dinamização da economia local, há que se atentar para o caráter sazonal da atividade e também para a forte dependência de mercados externos, de modismos globalizados e das tendências do turismo mundial. Dessa forma, uma localidade pode se transformar, de um momento para o outro, num importante destino turístico, recebendo um enorme fluxo de visitantes e provocando a migração de populações à procura de trabalho ou emprego de capital, como pode também, abruptamente, ser relegada ao abandono. O crescimento econômico relativamente rápido trazido pelo turismo tem iludido governantes, investidores e populações residentes. Deslumbrados com as possibilidades surgidas abandonam atividades tradicionais, vendo muitas vezes suas esperanças se evaporarem com uma rapidez jamais imaginada.

Em geral, mudanças também acontecem em relação às culturas locais. O contato com turistas vindos de grandes centros urbanos, com costumes e valores muito diferentes dos encontrados nos pequenos vilarejos, tem desencadeado intensa troca cultural. Essa troca leva a uma imbricação de universos culturais que, por sua vez, gera diferentes identidades (BARTH, 2000, p.21). No Aventureiro, a identidade dos agricultores/pescadores incorporou as de barqueiros transportadores de turistas, de donos de bar e de proprietários de áreas para camping. O bar e o camping, em particular, provocaram uma reorganização da casa e da família local. O espaço no entorno da casa, voltado unicamente para atividades domésticas - para o tratamento de produtos agrícola ou dos animais da família -, passou a ser ocupado também por pessoas estranhas, com outros hábitos, dividindo e invadindo a intimidade familiar. O contato com os jovens "de fora" tem influenciado os jovens da vila, provocando conflitos entre pais e filhos; conflitos esses que, agora, são menos freqüentes pelo fato de que os mais velhos estão se adaptando aos costumes externos. Entretanto, a dificuldade de se distinguir claramente as cidades dos pequenos vilarejos, a partir de critérios econômicos ou de hábitos culturais, não significa que esteja ocorrendo uma homogeneização que transformaria a distinção entre o rural e o urbano num continuum dominado pelo urbano (CARNEIRO,1998).

As transformações na comunidade rural provocadas pela intensificação das trocas com o mundo urbano (pessoais, simbólicas, materiais...) não resultam, necessariamente, na descaracterização de seu sistema social e cultural (...) Nessa perspectiva estão incluídas as possibilidades tanto da localidade sucumbir às pressões e interesses externos, mais potentes, como consolidar sua identidade local no confronto com o outro. A cultura local seria então resultado de um processo dinâmico em que seus elementos distintivos se articulariam com novos valores, hábitos e técnicas, em um movimento duplo, na medida em que há também a incorporação de elementos de outra "cultura rural" por parte de uma "cultura urbana" (CARNEIRO,1998, p.58-59).

Dessa perspectiva, as relações com os "de fora", ajudariam o grupo a definir sua identidade sustentada no pertencimento a uma localidade (CARNEIRO, 1998, p.62). A memória coletiva contribuiria com esse processo, informando sobre o reconhecimento de seu espaço próprio e identificando as mudanças adaptativas do grupo. A tradição "recontextualizada", vista não como uma volta ao passado e sim como uma nova leitura do presente, contribuiria para criar um espaço próprio, ao mesmo tempo que um espaço de acolhida (CARA, 1996, p.91).

\section{0 turismo no Aventureiro: um cenário sazonal}

Embora ao se analisar o turismo no Aventureiro como um fenômeno integrado ao que tem ocorrido em toda a região litorânea do sul fluminense seja necessário contextualizá-lo no universo social e histórico da Ilha Grande, também cabe fazer um distinção entre estes dois aspectos. Na Ilha Grande, o turismo guarda semelhanças com o que ocorreu de forma generalizada no litoral sul do estado do Rio de Janeiro. Nessa região, a construção da rodovia BR-101, no trecho Rio-Santos, foi um fator decisivo para o aparecimento do turismo de massa, contribuindo muito para o aumento da especulação imobiliária, num processo do qual a Ilha Grande não ficou imune.

Desde a década de 1970, havia um fluxo turístico não muito intenso para o local. Foi também nessa época a inauguração do primeiro hotel da região, na Vila do Abraão. Apesar da intensa atividade construtiva em toda a 
ilha a partir da desativação do presídio, os interesses econômicos mais pesados, para implantação de empreendimentos de grande porte, foram por diversas vezes coibidos. Para isso contribuíram as diversas leis ambientais, os decretos e as unidades de conservação. Simultaneamente, são cada vez mais constantes as iniciativas de pequeno porte, de contornos mais democráticos por representarem oportunidades para um número maior de pessoas com menor poder aquisitivo. Porém, a maneira desorganizada como isso vem ocorrendo tem causado forte impacto não só na paisagem mas também nas condições ambientais e na vida dos moradores da região. Em grande parte, isso ocorre porque o poder público não tem correspondido em termos de garantir infra-estrutura, planejamento e ordenamento da ilha capazes de dar conta dessa nova demanda. Assim, vão se avolumando os problemas relativos ao saneamento das áreas de concentração populacional. Dificuldades que se referem não apenas à coleta, tratamento e destinação do lixo, mas também à degradação ambiental, ao ordenamento do acesso dos visitantes, à regulação de obras e construções e à participação ou exclusão das populações locais das decisões sobre o próprio desenvolvimento da atividade turística.

No Aventureiro o processo é diferente. O turismo ainda é incipiente, mesmo que se tenha a impressão de que é exagerado o número de visitantes em algumas épocas do ano, como no carnaval, quando oscila entre $2.500 \mathrm{e}$ 3.000 pessoas. Esses números chamam a atenção, sobretudo. quando os relacionamos a um espaço físico de uns $800 \mathrm{~m}$ de praia. Entretanto, por ocorrer de forma reprimida, num lugar até agora interditado, o turismo no Aventureiro não se expandiu como em outras localidades da Ilha Grande. Diferentemente do que acontece em outras partes da ilha, lá, a hospedagem só é possível em camping.

Apesar do discreto crescimento no número de construções, a despeito de ser proibido construir ou mesmo ampliar as casas, não se nota ainda modificações significativas na paisagem. As casas seguem o padrão de distribuição da vila caiçara, em que a maioria delas é protegida pela vegetação e interligada por uma rede de caminhos. Como os meios de hospedagem existentes não são fixos (barracas de camping), o turismo no Aventureiro assemelha-se a um cenário que se monta e desmonta, periodicamente, apresentando intensidades diversas. Dependendo da época do ano, observa-se um número maior ou menor de barracas e uma aglomeração maior ou menor de pessoas, compondo, portanto, um cenário de maior ou menor agitação. Durante longas temporadas, principalmente, no inverno, não se encontra quase nenhum turista por lá.

Com a redução da atividade agrícola e, ultimamente, da pesca, os moradores viram no turismo diversas possibilidades de trabalho como alternativa de sobrevivência. Além das áreas de camping nos terrenos de suas casas, destacam-se o transporte de turistas nos barcos e a venda de refeições e bebidas. Com o passar do tempo e o envolvimento cada vez maior nessas atividades, alguns moradores têm procurado organizá-las e incrementá-las; um pouco a seu modo, um pouco sob influência de agentes externos.

Um aspecto importante que diferencia o turismo no Aventureiro do que é praticado no restante da Ilha Grande é que quase todos os que trabalham nessa atividade são moradores nativos. Salvo alguns recém-chegados e exmoradores que retornam na alta estação, são poucas as pessoas "de fora" conduzindo esse processo. Outro fator igualmente relevante é a sazonalidade. No Aventureiro ela é mais intensa por causa das más condições do mar durante o inverno, dificultando ou mesmo impedindo a circulação de barcos. Tais circunstâncias têm feito com que, mesmo com o intenso fluxo de visitantes no verão, a comunidade encontre tempo e sossego, na maior parte do ano, para se dedicar às suas práticas costumeiras e voltar ao seu ritmo tranqüilo de vida e à sua sociabilidade tão articulada pelas redes de parentesco. Nesse período, é possível cuidar melhor das roças, sair "pra pegar um peixinho" e participar na igreja da celebração com a ministra da eucaristia substituta do padre durante todo o ano.

Assim, os moradores do Aventureiro têm a oportunidade de preservar seu espaço e sua privacidade. Em outros momentos, porém, têm dificuldades em estabelecer limites, aceitando comportamentos com os quais não concordam, por medo de perderem a preferência dos turistas, como se os considerassem "um mal necessário". Convivem com eles sem maior envolvimento emocional, mantendo uma indiferença e um distanciamento que, às vezes, é quebrado quando o visitante tem uma conduta mais inconveniente.

A comunidade espera pelo turista, cuja chegada é de algum modo desejada, mas também temida. Muitos moradores vêem o turista como a "salvação" de sua vida penosa do passado, quando não havia dinheiro 
circulando. Por outro lado, também anseia pela partida do visitante. O afastamento dos turistas durante determinados períodos do ano é necessário para os moradores locais porque, como dizem, "quando é a época da alta, a vida muda muito". Essa atitude se explica pelo fato de que os hábitos dos visitantes ainda chocam os moradores da vila, embora muitos destes já tenham se acostumado com o barulho até altas horas e com a maneira como os turistas gostam de ser atendidos, sem respeitar o ritmo de vida local. Muitas vezes, os turistas são associados aos artistas da televisão, já incorporada ao dia-a-dia dos moradores do Aventureiro com a instalação de geradores a diesel nas casas, já que por estar numa reserva biológica, a vila não dispõe de eletricidade. Nesse sentido, a novela e os outros programas parecem ajudá-los a entender e a se relacionar com os turistas.

Para Rambaud (1969), a "sociedade urbana em férias" leva para o campo uma nova racionalidade, cria uma nova sociabilidade, suscita novas relações entre as famílias e os trabalhadores, gerando inquietude. Dessa mesma perspectiva, observa-se que as relações entre os nativos do Aventureiro sofreram adaptações. Eles próprios apontam, por exemplo, a falta de solidariedade, em comparação com as relações de vizinhança que tinham em outros tempos.

Pelo impacto que causa, o turismo no Aventureiro tem se transformado na grande preocupação dos ambientalistas governamentais e não-governamentais. Wunder (2000) mostra que, na pesquisa do Plano Diretor de Turismo da Ilha Grande (TANGARÁ1998), o turismo dos "mochileiros" foi o que causou o impacto mais negativo na Ilha, por sua infra-estrutura precária e principalmente pelo baixo retorno econômico. Todavia, o autor faz uma ressalva, ao afirmar que essa impressão possivelmente decorre muito mais de uma percepção subjetiva e estética do turista de luxo do que da realidade concreta. Se considerarmos que o aumento de novas construções é uma das conseqüências mais visíveis do turismo na Ilha Grande, podemos dizer que a forma de exploração dessa atividade no Aventureiro, com barracas que desaparecem por determinados períodos do ano, na verdade, causa menor impacto na paisagem e na população nativa, já que não gera especulação fundiária.

Quanto às outras preocupações, como por exemplo, em relação ao lixo deixado pelos turistas, Wunder (2000) alerta que é muito maior o volume de detritos trazidos pela maré, originado da poluição da baía da Ilha Grande e dos municípios vizinhos. Lembra ainda que esses problemas podem ser solucionados, promovendo-se uma maior conscientização de todos os envolvidos, inclusive da população local, e com a destinação de recursos para a remoção do lixo. Ressalta também que tal raciocínio igualmente se aplicaria às questões relativas ao fornecimento d'água e ao sistema de esgoto.

Outro problema colocado por alguns ambientalistas é a destruição da cultura caiçara. Numa análise sobre a inexorabilidade dos efeitos do turismo na cultura local, é necessário levar em conta, também, a densidade do sistema social e sua solidez, como propõe Rambaud (1969). Caso contrário, crer na idéia de um caráter "destrutivo" do contato entre universos culturais e sociais distintos pressupõe, de um lado, a passividade da cultura ou grupo social não-hegemônico e, de outro, a necessidade de se congelar no tempo as "sociedades tradicionais", para que se mantenham "tradicionais" ou "autênticas". Essa visão implica uma idéia de "pureza" ou de "autenticidade" das culturas que exclui a capacidade desses grupos assumirem a posição de atores sociais em face dos condicionantes a que estão submetidos. É importante enfatizar que o isolamento atribuído a essas comunidades é sempre relativo. No caso do Aventureiro, a relação com a cidade de Angra dos Reis já era freqüente e de longa data. Além disso, a pesca feita por empresas "de fora", desde meados do século XX - com a contratação de pescadores em diversos pontos da ilha - já interferia nos hábitos locais. Portanto, a questão exige uma reflexão mais aprofundada, que parece apenas ter começado.

Embora continuem a reproduzir sua cultura, por sugestão explícita ou não dos agentes "externos" que os valorizam como um "grupo caiçara", e também porque é assim que sabem e gostam de viver, sua forma de processar o que vem de fora é dinâmica, feita de reações, adaptações e assimilações. Não se pode afirmar com segurança que o turismo no Aventureiro esteja destruindo a cultura caiçara, mas certamente há uma forma própria desse grupo se relacionar com os turistas e com o mundo globalizado.

Reconhecer o pertencimento a um território levanta a discussão sobre a construção de identidades. De acordo com pontos de vista socioambientalistas, o território da comunidade no Aventureiro é o de uma "população 
tradicional", ou seja, um território "caiçara". Com a criação da reserva e o assédio dos turistas, essa identidade, ainda que atribuída, foi de certa forma assumida pela população nativa. Isso não acontece apenas porque é na relação com o outro e a partir da visão do outro - no jogo dialético entre semelhança e diferença - e na noção de identidade contrastante (OLIVEIRA, 1973) que as identidades são construídas. Devem ser igualmente consideradas as inúmeras oportunidades que essa população nativa tem tido de narrar seu passado e elaborar uma memória coletiva através das constantes perguntas dos pesquisadores, dos representantes do Estado, dos ambientalistas e mesmo dos turistas.

Nesse sentido, inferimos que a construção da identidade "caiçara" parece estar ligada à reconstrução do passado a partir de tensões e conflitos do presente (HALBWACHS, 1925), através de uma seleção de fatos lembrados, debatidos e atualizados e a partir de estímulos de agentes externos.

Existem no local duas principais frentes de sustentação dessa identidade que contribuem para reforçá-la. Uma é interna e se dá pelo contraste com os "de fora"; que é a de ser "o nativo", e portanto, "ter direitos", afirmando assim uma maior legitimidade em relação à permanência e à utilização dos recursos locais diante daqueles que chegaram para morar lá. A outra frente de sustentação se dá em relação aos agentes externos, pois é a de "ser nativo e ter direito ao lugar", defendendo-se, nesse caso, o direito de estar lá e usar esses recursos, sobretudo perante o Estado, principal questionador desses direitos. Nesse sentido, ao mesmo tempo em que ocorrem mudanças nos hábitos desse grupo, é reforçada uma identidade que os reafirma como grupo diferenciado.

A apreensão do espaço por outros atores, definindo um território de interesse da preservação e um de interesse do turismo, configura outro território também para a tradição. A existência de duas unidades de conservação, uma relativa ao mar, onde se pesca, e outra à terra, local das roças, estabelecendo controles sobre os principais elementos de identificação dessa sociedade, implicou mudanças substanciais. Na reprodução social das famílias, além de determinar a busca de alternativas econômicas, a existência dessas unidades impôs uma reelaboração das classificações sobre a natureza e a sociedade a partir das classificações trazidas pelo ambientalismo. Brandão (1999) fala de uma "gramática" das "relações de troca entre os seres do campo e do mato" e as pessoas. Antes da criação da reserva, a terra era o lugar das roças. Os animais tinham suas classificações; alguns eram domesticados, outros eram caçados, e havia os que eram temidos. Muitas plantas da mata ao redor das roças tinham uso medicinal, dentre outras utilidades, enquanto outras eram nocivas e evitadas. Para Brandão (1999, p.74), "mais do que classificações segundo relações de perigo e utilidade, os animais sugerem sentimentos pela figura do que são ou pela metáfora do que foram em outra dimensão de suas próprias imagens e idéias para uma dada cultura". Assim, nos locais onde existiam "as roças", passaram a existir "os ecossistemas"; os "bichos" agora são "espécies a serem preservadas" e a "capoeira" se transforma em "floresta em regeneração".

A presença de turistas, de pessoas para quem o tempo de lazer corresponde ao tempo de trabalho do homem local, também contribui para a transformação pela qual passa essa população. O turista traz hábitos estranhos, necessidades a serem atendidas, dinheiro, barulho, lixo e poluição. Necessidades e hábitos que em parte vão sendo incorporados ao universo nativo. O dinheiro que vem do turismo traz a energia elétrica dos geradores, e com ela chega também a televisão e um mundo de informações e valores.

Percebemos, assim, como a presença do "outro" no território nativo cria outros territórios simbólicos que se interconectam e promove uma reconstrução constante das identidades. É útil lembrar ainda que esse território nativo, como já mencionado, é uma construção anterior de outros sujeitos em interação. A agricultura extensiva e rotativa teve que ser restringida, a extração de espécies florestais utilizadas de diversas maneiras, inclusive terapêuticas, foi reprimida, assim como também a caça, a extração de areia etc. No entanto, apesar de todas essas restrições impostas pela legislação, a agricultura e a pesca são nuclearizadoras dos processos de construção de identidade, sendo praticadas e valorizadas por boa parte desse grupo social, a despeito de não serem mais as únicas nem as principais fontes de renda dessa população. 


\section{Conclusão}

Neste estudo procuramos analisar especificamente o turismo na Vila do Aventureiro, contrapondo-o ao da Ilha Grande. Freqüentemente, aquele tem sido visto como continuidade do que ocorre no restante da ilha, o que aqui é contestado. O fato de estar associado a uma unidade de conservação tão restritiva como é o caso de uma reserva biológica, o difícil acesso ao local e a coesão interna do grupo determinam a especificidade daquela localidade, se comparada com o contexto geral da ilha. Assim, a intervenção cuidadosa de políticas públicas que respeitem e considerem seus aspectos socioculturais, dispostas a construir, em conjunto com a população local, um projeto conservacionista inclusivo, poderá garantir uma qualidade de vida digna para a população da Vila do Aventureiro, fazendo com que ela participe da conservação ambiental da área.

Enquanto o turismo na ilha é, em geral, explorado principalmente por pessoas de fora, com maior poder econômico e melhores condições sociais, no Aventureiro isso é feito pela população local, a partir de sua própria experiência de vida, articulando suas referências culturais com os valores, as informações e as demandas dos turistas. Na ilha, a especulação imobiliária domina a cena, transformando o espaço de forma rápida e radical. No Aventureiro, essa demanda é reprimida e as modificações espaciais socorrem lentamente e de forma controlada. O forte impacto ambiental e paisagístico fica limitado ao período de verão e, a alguns feriados, pois é praticamente nulo nos outros períodos do ano, especialmente no inverno. Logo, a população local tem maior autonomia em relação ao turismo, conseguindo preservar melhor sua coesão interna e seus elementos culturais.

Embora os nativos estejam modificando seus hábitos e costumes, tomando como modelo o estilo de vida dos turistas - principalmente as crianças e os jovens -, e expandindo sua rede de relações sociais, também se observa a afirmação de uma identidade diferenciada. Essa identidade se manifesta por uma valorização do pertencimento ao lugar, do compartilhar um universo simbólico comum e de suas regras e interdições culturais e, ainda, pela diferenciação que estabelecem entre si próprios e os "de fora". Essa identidade é, também, reafirmada através de suas práticas agrícolas e pesqueiras, pela sociabilidade baseada nos laços de parentesco e na solidariedade entre as famílias.

A discussão aqui proposta também envolve a idéia de que o Aventureiro é lócus de uma disputa por hegemonia entre diferentes valores e significados e pelo direito de seu uso pelos grupos a eles associados. O local tem sido igualmente visto como espaço de preservação e de desfrute, percepções que entram em choque com as da comunidade nativa. Este estudo aponta os diversos campos ideológicos presentes, configurando territórios sociais que se entrelaçam e se redefinem. Procura analisar o que implicam essas diferentes concepções sobre a vida da população local e entender as expectativas a esse respeito, muito marcadas por uma perspectiva de conservação ambiental e cultural, enquanto atuam como elementos dinamizadores e provocadores de mudanças.

Se ao impor limites ao turismo a rígida legislação das unidades de conservação locais contribui para que o Aventureiro seja diferente de outras áreas da Ilha Grande, também acaba limitando as possibilidades de dotar o local de infra-estrutura relativa à saúde e ao fornecimento de energia elétrica, serviços considerados tão importantes pela população. Isso impossibilita não só o planejamento da atividade turística, mas também que se proponha políticas públicas para seu ordenamento. A médio prazo, essa desorganização e a dificuldade de controlar o crescimento da atividade turística pode causar impacto ambiental e social negativos irreversíveis.

Portanto, o que deve ser destacado não é a possibilidade das populações ditas tradicionais manterem sua cultura livre de influências do mundo globalizado, criando-se uma "reserva cultural". Esse contato não resulta necessariamente na anulação da cultura local, mas pode apontar também para uma aglutinação em torno de elementos locais como uma reação à urbanização e à globalização. O que se coloca é o direito dessas populações decidirem como desejam se inserir nesse mundo globalizado, podendo, inclusive, negar aspectos que não lhes convenham, permeando com sua visão de mundo, projetos de conservação ambiental que as incluam e viabilizem relações menos desiguais com esse mundo "exterior". 


\section{Referências bibliográficas:}

BARTH, F. 0 guru, o iniciador e outras variações antropológicas. Rio de Janeiro: Contracapa, 2000.

BRANDÃO, C. R. 0 afeto da terra. Campinas: Editora Unicamp, 1999.

BRASIL. Ministério do Meio Ambiente. SNUC - Sistema Nacional de Unidades de Conservação. Lei no 9.985/2000. Brasilia, DF: SNUC, 2000.

BRASIL. Ministério do Meio Ambiente. SNUC - Sistema Nacional de Unidades de Conservação. Decreto no 4.340/2002. Brasilia, DF: SNUC, 2002.

CARA, R. B. El turismo y los procesos de transformación territorial. In: RODRIGUES, A. B. (Org.).Turismo e geografia: reflexões teóricas e enfoques regionais. São Paulo: Huicitec, 1996.

CARNEIRO, M. J. Ruralidade: novas identidades em construção. Estudos, Sociedade e Agricultura, Rio de Janeiro, CPDA, n.11, 1998.

CAVACO, C. Turismo rural e desenvolvimento local. In: RODRIGUES, A. B. (Org.). Turismo e geografia: reflexões teóricas e enfoques regionais. São Paulo, Huicitec, 1996.

CEBALLOS-LASCURÁIN, H. 0 ecoturismo como um fenômeno mundial. In: Ecoturismo - um guia para planejamento e gestão. São Paulo: Editora Senac, 1995.

DIEGUES, A. C. 0 mito moderno da natureza intocada. São Paulo: Huicitec, 1996.

DURÁN, F. E. Viejas e nuevas imágenes sociales de ruralidad. Estudos, Sociedade e Agricultura, Rio de Janeiro, CPDA, n.11, 1998.

FEEMA. Reserva Biológica da Praia do Sul - Ilha Grande. [S.I.]: Decam-Divipe, 1982.

GEIGER, P. P. Turismo e espacialidade. In. RODRIGUES, A. B. (Org.). Turismo e geografia: reflexões teóricas e enfoques regionais. São Paulo: Huicitec, 1996.

HALBWACHS, M. Les cadres sociaux de la mémoire. Paris: Presses Universitaires de France, 1925.

KAYSER, B. La renaissance rurale: sociologie des campagnes du monde occidental. Paris: Armand Colin, 1990.

KRIPPENDORF, J. Sociologia do turismo. Rio de Janeiro: Civilização Brasileira, 1989.

MACIEL, N. C.; ARAÚJO, D. S. D.; MAGNANINI, A. A situação dos ecossistemas das praias do Sul e do Leste, na Ilha Grande, município de Angra dos Reis (RJ), com vistas à preservação. Rio de Janeiro: Feema, 1980.

MOREIRA, R. J. Ruralidades e globalizações. [S.I.]: CPDA Ruralidades, 2002.

MORMONT, M. L'environnement entre localité et globalité. In: Mobilités et ancrages. Paris: L'Harmattan, 1996.

NICOLAS, D. H. Elementos para un analisis sociogeografico del turismo. In: RODRIGUES, A. B. (Org.). Turismo e geografia: reflexões teóricas e enfoques regionais. São Paulo: Huicitec, 1996.

OLIVEIRA, R. C. Um conceito antropológico de identidade. Alter, Vol 3 nº 4, Brasilia, UNB, 1973.

RAFFESTIN, C. Écogénèse territoriale et territorialité. In: AURIAC, F.; BRUNET R. Espaces, jeux et enjeux. [S.I.]: Fondation Diderot/Fayard, 1986.

RAMBAUD, P. Societé rurale et urbanization. Paris: Editions du Seuil, 1969.

SEMADS - RJ. Atlas das unidades de conservação da natureza do estado do Rio de Janeiro. São Paulo: Metalivros, 2001.

TANGARÁ. Serviços em meio ambiente e turismo, llha Grande -Plano Diretor de Turismo, 1998.

URBAN, T. Saudade do Matão: relembrando a história da natureza no Brasil. Paraná: Editora UFPR, 1998.

WUNDER, S. Big Island, green forests and backpackers. [S.I.]: Ipea, 2000. 